\title{
Epigenetic mechanisms underlying prostate cancer radioresistance
}

\author{
Catarina Macedo-Silva 1,2, Rosaria Benedetti ${ }^{1}$, Fortunato Ciardiello', Salvatore Cappabianca', \\ Carmen Jerónimo $2,3^{*}$ (1) and Lucia Altucci ${ }^{i^{*}}$ (B)
}

\begin{abstract}
Radiotherapy (RT) is one of the mainstay treatments for prostate cancer ( $\mathrm{PCa}$ ), a highly prevalent neoplasm among males worldwide. About 30\% of newly diagnosed PCa patients receive RT with a curative intent. However, biochemical relapse occurs in 20-40\% of advanced PCa treated with RT either alone or in combination with adjuvant-hormonal therapy. Epigenetic alterations, frequently associated with molecular variations in $\mathrm{PCa}$, contribute to the acquisition of a radioresistant phenotype. Increased DNA damage repair and cell cycle deregulation decreases radio-response in PCa patients. Moreover, the interplay between epigenome and cell growth pathways is extensively described in published literature. Importantly, as the clinical pattern of PCa ranges from an indolent tumor to an aggressive disease, discovering specific targetable epigenetic molecules able to overcome and predict PCa radioresistance is urgently needed. Currently, histone-deacetylase and DNA-methyltransferase inhibitors are the most studied classes of chromatin-modifying drugs (so-called 'epidrugs') within cancer radiosensitization context. Nonetheless, the lack of reliable validation trials is a foremost drawback. This review summarizes the major epigenetically induced changes in radioresistant-like PCa cells and describes recently reported targeted epigenetic therapies in pre-clinical and clinical settings.
\end{abstract}

Keywords: Epigenetics, Epidrugs, Radioresistance, DNA repair, Prostate cancer

\section{Introduction}

Prostate cancer $(\mathrm{PCa})$ remains highly prevalent among males worldwide. Despite relatively low mortality rates, this malignancy is the second most common cancer in men, mostly due to the current widespread intensive prostate-specific antigen (PSA) screening [1,2]. According to Globocan estimates, around 1.4 million new cases of $\mathrm{PCa}$ were diagnosed in 2020 [2].

\footnotetext{
*Correspondence: carmenjeronimo@ipoporto.min-saude.pt; cljeronimo@icbas.up.pt; lucia.altucci@unicampania.it

${ }^{1}$ Department of Precision Medicine, University of Campania "Luigi

Vanvitelli", Vico L. De Crecchio 7, 80138 Naplei, Italy

${ }^{2}$ Cancer Biology and Epigenetics Group, Research Center at Portuguese Oncology Institute of Porto, F Bdg, 1st Floor, Rua Dr. António Bernardino de Almeida, 4200-072 Porto, Portugal

Full list of author information is available at the end of the article
}

Radiotherapy (RT) using external beam radiation therapy (EBRT) is considered a first-line standard treatment with curative intent for PCa patients, and is often performed with moderate hypofractionation therapeutic schemes using fraction sizes larger than 2 Gy delivered daily [3]. Relapse is a major clinical problem in locally advanced $\mathrm{PCa}$ and for both intermediate-risk and highrisk PCa (HRPC) patient's, prognosis is significantly worse. Between 20 and $40 \%$ of patients treated with RT experience long-term recurrence within a 5-year followup [4]. Despite considerable efforts to develop effective therapeutic strategies, improvements in precision medicine techniques are still needed and represent the next step toward enhancing clinical management of resistance to first-line therapies.

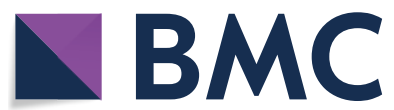

(c) The Author(s) 2021. Open Access This article is licensed under a Creative Commons Attribution 4.0 International License, which permits use, sharing, adaptation, distribution and reproduction in any medium or format, as long as you give appropriate credit to the original author(s) and the source, provide a link to the Creative Commons licence, and indicate if changes were made. The images or other third party material in this article are included in the article's Creative Commons licence, unless indicated otherwise in a credit line to the material. If material is not included in the article's Creative Commons licence and your intended use is not permitted by statutory regulation or exceeds the permitted use, you will need to obtain permission directly from the copyright holder. To view a copy of this licence, visit http://creativecommons.org/licenses/by/4.0/. The Creative Commons Public Domain Dedication waiver (http://creativeco mmons.org/publicdomain/zero/1.0/) applies to the data made available in this article, unless otherwise stated in a credit line to the data. 
Dynamics of ionizing radiation (IR) response is mainly associated with DNA damage pathways [5]. Hypoxic foci, PCa stem cell (PCSC) population, and neuroendocrine differentiation (NED) involved in DNA repair/apoptosis and cell cycle deregulation play a major role in radioresistance [6]. Epigenetic reprograming in PCa may also contribute to the regulation of these functional pathways [7]. Understanding how this phenotypic switch occurs and enhances radioresistance in a PCa subpopulation has been a critical research focus during the past years. Since epigenetic dysregulation is a key mechanism underlying cancer cell death escape after RT, the identification of novel epigenetic targets and new epidrugs might increment personalized clinical management [7].

In this review, we discuss the latest pre-clinical and clinical insights into the role of epigenetics in Pca radioresistance. Specifically, we focus on recent advancements in PCa's understanding, from the molecular machineries driving radiation response based on tumor biology to epigenetic alterations involved in cell death and DNA damage pathways, all of which might impact Pca patient outcome. We also described the benefits of strategies using so-called epidrugs concurrently administered with standard RT.

\section{The importance of radiotherapy in prostate cancer care}

Unlike other cancers, slowly proliferating tumors, such as $\mathrm{PCa}$, could be highly responsive to larger radiation fraction sizes and in many cases RT constitutes the standard of care for PCa [8]. Although a meta-analysis of 25 studies including $>14.000$ patients concluded that hypofractionated RT could be more effective than conventional fractions of 1.8/2 Gy [9] the major phase III trials of moderate hypofractionation did not demonstrated superiority in terms of both outcomes and toxicity (HYPRO, phase III randomized trial, ISRCTN85138529). At the same time, the hypofractionated approach, due to the added advantages of being more convenient for patients with a lower cost, has become the standard practice in the clinical management of PCa patients. Similar to normal healthy tissues with low proliferative rates, such as, kidney, lung, rectum, bladder, and brain, $\mathrm{PCa}$ has a long cell cycle, which confers higher damage repair efficiency and capability [8]. In fact, PCa exhibits a longer doubling time than other tumors, with a much lower fraction size $(\alpha / \beta$ ratio) of 1-2 Gy [9]. Thus, taking together radiobiological assumptions for tumor control and dose limitations of surrounding normal tissue, hypofractionation schedules in RT treatment planning might improve PCa therapeutic efficacy [8].

Recent innovative three-dimensional RT techniques, such as intensity-modulated radiation therapy (IMRT) and volumetric-modulated arc therapy (VMAT) using image-guided RT (IGRT), are overcoming previous limitations of higher dose administration schemes that resulted in late complications and tumor-related morbidities, considering the proximity of prostate gland to bladder and bowel wall [10-12]. Although conventional EBRT doses are delivered in 37-40 fractions with total delivery doses of 76-80 Gy [13], moderate to extreme hypofractionation schemes using larger daily fractions with ablative doses are reported to be more convenient in terms of costs and convenience for the patients, being non inferior in terms of both outcomes and acute/late toxicity [10].

Another approach of increasing the therapeutic ratio of RT for PCa consists of dose-escalation. Zelensky et al. in a retrospective analysis of 2551 patients with different risk categories demonstrated that biochemical disease free survival (bDFS) was significantly improved by dose escalation (above $81 \mathrm{~Gy}$ for the intermediate and HRPC) [14]. The FLAME trial is currently evaluating the efficacy of an integrated boost delivery of 95 Gy in multiparametric (mp) MRI-defined tumors and has shown no significant toxicities increment. Another approach of dose-escalation consists of the delivery of a high-dose rate boost of brachytherapy after, with good outcomes in terms of control of the disease [8].

Several findings support the advantages of androgendeprivation therapies (ADT; gonadotropin-releasing hormone agonists/antagonists, abiraterone, and antiandrogens/androgen receptor [AR] antagonists) in concomitance with RT to improve overall survival rates and reduce the risk of long-term biochemical recurrences [15]. The combination of ADT with RT has definitively proven its superiority compared with RT alone followed by salvage ADT in different phase III RCTs (RTOG8610 and TROG96.01, randomized clinical trials), so that for intermediate risk PCa patients a short duration of around 6 months is advised, whereas a longer one (2-3 years) is needed for HRPC patients.

Another strategy that could improve the therapeutic efficacy in HRPC patients is the addition of chemotherapy (docetaxel) to standard RT plus ADT for a defined subset of HRPC (STAMPEDE, randomized controlled trial), although subsequent meta-analysis did not confirm the advantage in overall survival [16].

Despite the aforementioned different strategies, a significant percentage of patients progress to a castrationresistant phenotype after 2-3 years of ADT initiation, worsening the patient's prognosis [16]. Notwithstanding advances in therapeutic management, PCa patients with high-grade tumor burden display high progression rates and consequently a greater risk of treatment failure [16]. Hence, the discovery of critical targets of unravelled 
molecular patterns is urgently required to predict and overcome radioresistance in this malignancy.

\section{Intrinsic molecular pathways involved in $\mathrm{PCa}$ during therapeutic radiation exposure}

Considering the high degree of PCa's histopathologic heterogeneity, RT resistance poses a major clinical challenge due to the likely development of an aggressive disease. The dynamics of successful tumor irradiation are defined by the classic R's of radiobiology: Repair of sublethal damage, Redistribution of sensitive cell cycle phases, Repopulation, and Reoxygenation of hypoxic tumor cells (Fig. 1) [17]. As discussed above, slow proliferating tumors as PCa have a greater capacity for damage repair due to intrinsic longer cell division time [8]. All aforementioned R's can be affected by the establishment of innovative therapeutic schemes [18]. Herein, hypofractionated approaches with higher doses per fraction might overcome the problematic of late responding tissues [18]. Latest reduced treatment time schedules should maintain elevated biological effective doses (BED) without increasing either acute or late side effects for late-responding normal tissues, which limits therapeutic designs $[18,19]$. An equilibrium between minimum normal surrounding tissue damage and efficient tumor local control must be considered [18]. Using higher doses, cell toxicity and death are typically more pronounced [18]. DNA is the most critical IR target, promoting intrinsic genomic instability mainly through the generation of DNA double-strand breaks (DSBs) [20]. DNA DSB repair is mediated through two major pathways, homologous recombination (HR) and non-homologous end joining (NHEJ) [20]. Changes in the normal cell division functioning affect DNA damage repair (DDR) processes [20]. The following subsections describe the major cellular mechanisms involved in $\mathrm{PCa}$ radioresistance.

\section{DNA repair and apoptosis}

The most accurate DNA repair pathway, HR, is activated during late $S$ phase of the cell cycle, starting from the

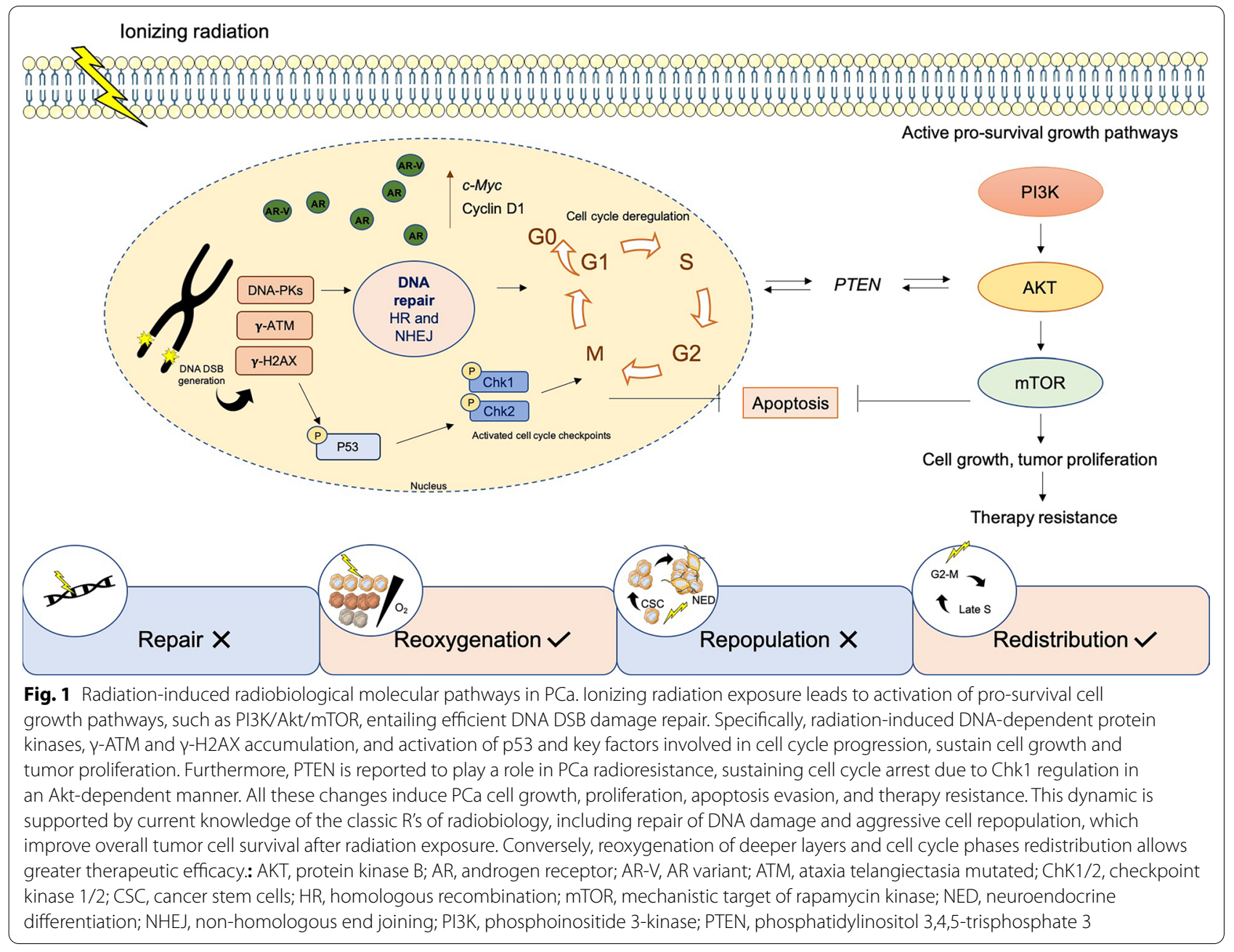


recruitment of several key proteins, such as autophosphorylated ataxia telangiectasia mutated ( $\gamma$-ATM), DNAdependent protein kinases, $\gamma-\mathrm{H} 2 \mathrm{AX}$, breast cancer gene 1/2 (BRCA1/2), poly(ADP-ribose) polymerase 1 (PARP1 ), and RAD51 [21]. Defects in DDR pathways are commonly described as PCa drivers [21, 22]. Between 15 and $30 \%$ of PCa's display DDR instability, involving the most common pathways such as mismatch repair (MMR), base-excision repair (BER), and NHEJ/HR for DSBs [23]. Specifically, DDR gene mutations were commonly found in metastatic castration-resistant $\mathrm{PCa}(\mathrm{CRPC})$ patients [24]. Impaired DNA damage repair may provide RT escape mechanisms of tumor cells. Specifically, RAD51 - Stat $5 a / b$ transcriptional regulation led to efficient DSBs DNA damage repair in PCa after IR exposure [25]. Targeting this axis significantly reduced survival [25]. Involvement of phosphoinositide 3-kinase/protein kinase $\mathrm{B} /$ mammalian target of rapamycin (PI3K/Akt/mTOR) pro-survival signaling pathway as well as overexpression of critical cell growth and cell cycle progression factors, including $c-M y c$ and $c y c l i n D 1$, have been implicated in PCa radioresponse's regulation [26]. Additionally, activation of cell cycle checkpoint kinases Chk1 and Chk2 in a radioresistant $\mathrm{PCa}$ subpopulation was found to enhance cancer stemness features, increased invasion and epithelial-mesenchymal transition (EMT) [27].

In contrast, phosphatidylinositol 3,4,5-triphosphate 3-phosphatase (PTEN), proteins involved in the caspases cascade, and apoptotic proteins are key mediators in tumor cell death [20,28]. Nonetheless, most of these proteins are mutated or epigenetically silenced during IR exposure, resulting in apoptosis evasion [28]. Indeed, disturbances in several steps of these signaling pathways were shown to augment tumor aggressiveness, reducing RT response [20, 28]. HMG-box transcription factor 1 (HBP1) and PTEN work as tumor suppressors allowing transcription inhibition [20,29]. Positive correlation between $H B P 1$ expression and RT efficacy was reported in a previous work [29]. PTEN is a key tumor suppressor gene (TSG) and negative Akt's regulator found altered in PCa [20]. Intriguingly, although PTEN mutations are reported to contribute to tumor progression, PTEN phosphatase activity was suggested to be implicated in HR, DDR, and cell cycle arrest through Akt-dependent $\gamma$-CHK1 signaling regulation [20]. Additionally, tumor protein p53, another key dual-function protein, cell cycle and apoptosis regulator, undergoes alterations during radiation-induced DNA damage response in $\mathrm{PCa}[30$, 31]. Specifically, p53 pathway upregulation was observed in PCa cells after IR exposure [30, 31]. Interestingly, p53 wild-type cells significantly reduced clonogenic capacity under RT exposure after E2F-1 transcription factor targeting [32]. These data were further supported and enriched with the combination of $M D M 2$ knockdown, a negative regulator of p53, resulting in $\gamma$-p53 (serine 15) enhancement [33]. Otherwise, functional phosphorylated p53 was able to prolong G1-S and G2-M cell cycle arrest, giving cells sufficient time for DDR and thus contributing to tumor cell repopulation after RT [30].

Thus, the aforementioned alterations enable tumor cells to evade mechanisms of programmed cell death, promoting recovery and repopulation between RT fractions. Direct or indirect targeting these pathways and their downstream regulators was suggested to improve $\mathrm{PCa}$ radiosensitization $[20,28]$. Of note, $20 \%$ of $\mathrm{PCa}$ patients display PTEN loss-of-function mutations [34]. Driver mutations in ETS transcription factor through gene fusion played a key role in PCa [35]. ERG-ETS family member increased PARP-1 activity resulting in less DNA damage and PCa radioresistance [35]. HR- and BER-defective PCa can benefit from targeted therapy with PARP inhibitors [34], such as Olaparib and veliparib, as supported by clinical trials. Nonetheless, only pre-clinical studies shown the role of these drugs as $\mathrm{PCa}$ cells radiosensitizers [35-39].

\section{Hypoxia and PCa}

Hypoxia is among the most relevant factors implicated in radioresistance and cell death escape [40, 41]. Considering the intrinsic heterogeneity of cell radiosensitivity, hypoxic foci are commonly found in both prostate hyperplasia and adenocarcinoma [42]. Theoretically, during fractionated RT, the deeper tumor layers usually farther from blood vessels become increasingly oxygenated [43]. However, for extremely hypoxic tumors with oxygen pressure $\left(\mathrm{PO}_{2}\right) \leq 1 \mathrm{mmHg}$, standard fractionated therapy was estimated to be successful in only $\sim 15 \%$ of $\mathrm{PCa}$ patients [42]. Furthermore, hypofractionated schemes with reduced fractions might affect reoxygenation [43]. Therefore, the success rates achieved with hypofractionated schemes are not yet fully understood in PCa [42].

From a molecular point of view, hypoxia can activate a complex cellular signaling network in several tumors. The absence of oxygen was associated with hypoxia-inducible factors (HIFs) overexpression, triggering the activation of several downstream hypoxic responsive elements, such as vascular endothelial growth factor (VEGF), carbonic anhydrase IX (CAIX), and glucose transporter 1 (GLUT-1), allowing cells to adapt to the hypoxic microenvironment [44]. Severe hypoxia in the PCa niche during radiation exposure led to overall genomic instability (Fig. 1) [44]. DSBs are expected to appear after RT exposure, damaging DNA [45]. Interestingly, in hypoxic cells, along with reactive oxygen species (ROS) scavenging, the tumor microenvironment also it modulates DDR pathway [46-48]. Additionally, microenvironmental redox 
statement led to differential expression of NrF2 and their downstream targets allowing PCa radioresistance [49]. Conservative HR pathways and respective downstream targets were strongly deregulated both in chronic hypoxia and reoxygenation to refrain from radiation-induced cell's death [47]. Two key HR genes, BRCA1 and RAD51, as well as, the MMR genes $M L H 1$ and $M S H 2$ were also downregulated in hypoxia $[45,47]$. This genetic instability leads to errors through cell cycle checkpoints, maintaining tumor progression at a high mutational rate [47]. These include genetic aberrations such as point mutations or gene amplification [47]. Indeed, highly hypoxic PCa presents a stout reduction of PTEN transcription and increased mutational burden [50].

Furthermore, PI3K/Akt/mTOR and mitogen-activated protein kinase/extracellular regulated kinase (MAPK/ ERK) are critical cell signaling pathways activated during hypoxia stabilization in PCa to regulate HIF synthesis [44]. VEGF expression was also reported to be induced after PI3K activation in a HIF-dependent manner and via Notch cascade signaling activation, even in oxygen-independent conditions, due to $V H L, p 53$, and PTEN mutations or loss of function [44,51]. Additionally, several key DDR-related genes, including $A T M / A T R, C h k 1 / 2$, $\gamma-\mathrm{H} 2 \mathrm{AX}$, and $\mathrm{Ku} 70 / 80$, were upregulated in hypoxic cells, mainly through NHEJ repair pathway [47].

\section{PCa stemness}

PCa RT responsiveness was also regulated by a subpopulation of cells with stemness properties within tumor bulk [52]. Indeed, these cancer stem cells (CSCs), also known as tumor-initiating cells, are AR-independent and commonly maintained into the hypoxic tumor microenvironment [52-54]. These $\mathrm{CD}_{4} 4^{+}$and $\mathrm{CD} 133^{+}$cells persist after RT, promoting tumor progression and early biochemical recurrences [55]. Moreover, its avoided apoptosis and other radioresistant associated features (Fig. 1) [52]. The PCSCs specific-associated pluripotency genes, SOX2, OCT3/4, KL-F4, c-Myc, Nanog, and Snail were shown to be useful to identify recurrent patients after RT [27]. Indeed, these pluripotency-associated markers and EMT-associated molecules are induced by the HIF signaling network [56]. Furthermore, PI3K/Akt/mTOR and MAPK/ERK are commonly activated signaling pathways associated with PCSC growth and therapy evasion [57].

CSCs are distinguished by a constant quiescent state of the cell cycle (G0/G1), contrasting with the rapid cell division required RT effectiveness. Of note, defects in DDR pathways have been often observed in PCSCs [55]. An imbalance between low levels of intracellular ROS-produced DNA damage and higher DDR efficiency through $\gamma$-H2AX, Ku70, and Ku80 was also described in PCSCs after RT [55]. Cell cycle and DDR defects implicate in PCSCs radioresistance. Remarkably, Chk1 Knockdown prevented G2-M radiation-induced cell cycle arrest, decreasing DDR, while inducing apoptosis in a $\mathrm{CD} 133^{+} / \mathrm{CD} 44^{+}$subpopulation [58].

\section{PCa neuroendocrine differentiation}

NED is a frequent transitory event in CRPC associated with treatment failure $[59,60]$. Currently, NED is accepted to be the most aggressive clinical variant form of PCa [59]. Approximately $1 \%$ of primary PCa is classified as NED tumors at diagnosis, whereas about $30 \%$ of advanced PCa patients display neuroendocrine transitory foci $[61,62]$. This phenotype is characterized by the loss of characteristic markers of the prostate gland, such as AR and PSA [63]. Instead, AR-null PCa cells display increased NED markers'expression [64]. AR-dependent signaling is compensated in neuroendocrine $\mathrm{PCa}$ (NEPC) through enhanced activity of cell-sustaining growth factors, such as fibroblast growth factor and MAPK [64]. Consequently, as NEPC's biology is not fully understood, effective treatment options are very limited. Nevertheless, cisplatin-based chemotherapeutic is routinely used to reduce tumor burden in these patients [62].

Radiation exposure was also reported to induce NEPC differentiation [65]. Additionally, NE-like cells transdifferentiation upon fractionated radiation exposure have been linked with the dynamic regulation of transcription factors, such as, AMP-response element binding protein (CREB) and activating transcription factor 2 (ATF2), at nuclear (active form) and cytoplasmatic location (inactive form), respectively [66]. Furthermore, CREB inhibition led to the blockage of IR-induced NED and radiosensitize PCa cells inducing cell death [67]. Similarly to PCSCs, NEPC cells are quiescent [68], also suggesting great ability to DDR after radiation exposure. Globally, NEPC cells are molecularly characterized by $N-M y c$ overexpression, which drives the transcriptional enrichment of HR DDR and stress-related genes, such as BRCA1, PARP1/2, RecQ-mediated genome instability 2 (RMI2), and DNA topoisomerase II binding protein 1 (TOPBP1) [59]. Furthermore, TP53, PTEN, and retinoblastoma (RB1) loss of function were found in NEPC tumors [69]. This leads to blockage of pathways related to cell growth and proliferation inhibition, including interleukin 8-mediated IL-8/ CXCR2/p53-pathway and further increasing aggressive properties of neuroendocrine malignancies [68]. Moreover, tumor plasticity plays a central role in NED due to the enhancement of EMT-induced pathways, with the activation of ZEB1/2, Snail, Slug, Twist, and N-cadherin [69]. These tumor cells have the ability to adapt, bypassing barriers, and becoming increasingly aggressive. Previous studies showed that both ADT and RT promote 
hypoxia-related CSC, strongly contributing to heterogeneous disease and consequently RT failure [70, 71].

Overall, lethal NEPC represents a hurdle to both RT/ ADT therapy. Hence, the study of these patients' epigenetic profile might allow for the identification of RT responders and non-responders markers, considering the previously mentioned molecular pathways involved in radioresistance.

\section{Epigenetics in PCa: a brief overview}

Epigenetic alterations induce reversible and heritable changes promoting differences in gene expression without changing DNA sequence [72]. They are generally classified as a constitutive hallmark of cancer, due to the combined action of oncogene activation and TSG knockdown [72]. DNA methylation, covalent histone-modifications, histone-variants and chromatin remodeling complexes are commonly accepted epigenetic mechanisms [72]. Nonetheless, PCa displays complex epigenetic landscape deregulation associated with changes in cell growth pathways and overall tumor progression (Fig. 2) [72].

\section{DNA methylation}

DNA methylation is the major epigenetic mechanism described in cancer [73]. Differential methylation levels among distal and genic regions are key dynamic drivers of $\mathrm{PCa}$ tumorigenesis and progression [74]. This process involves the addition of a methyl group to 5 -methylcytosine $(5 \mathrm{mC})$, usually at the promoter region, in CpG-enriched islands, to promote gene silencing [72]. This reaction is catalyzed by DNA methyltransferases (DNMTs), including DNMT1, often associated with DNA methylation maintenance, and DNMT3a and DNMT3b, responsible for de novo methylation [72]. In contrast, DNA methylation is reversed by teneleven translocation (TET) enzymes [75]. In PCa, global DNA hypomethylation has been widely reported [76, 77]. Additionally, long interspersed nuclear element-1 (LINE-1) a gene frequently silenced in the normal human genome, is re-expressed in PCa cells [77]. Conversely, hypermethylated foci in specific TSG promoter regions were associated with gene silencing (Fig. 2A) [72]. DNMTs, particularly DNMT3a and DNMT3b, were highly expressed in $\mathrm{PCa}$ and associated with tumor

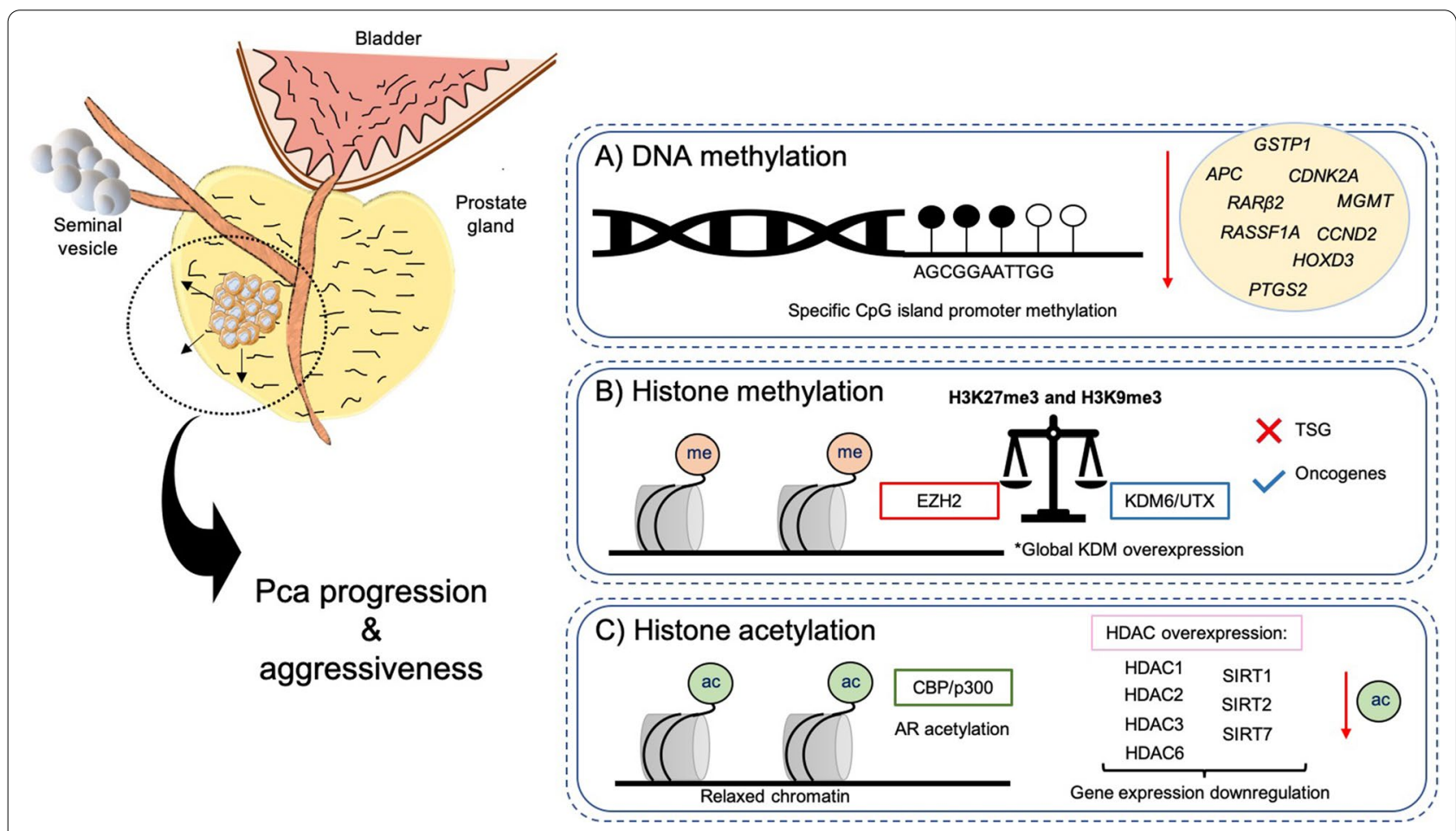

Fig. 2 Epigenetic landscape in PCa. Aberrant DNA methylation (A) and histone post-translational modifications (B, C) lead to overall PCa progression and aggressiveness due to uncontrolled gene transcription signature. Black filled circles represent methylated sites (A). ac, acetylation; $A P C$, adenomatous polyposis coli; AR, androgen receptor; CBP, CREB-binding protein; CCND2, cyclin D2; CDNK2A, cyclin-dependent kinase inhibitor 2A; CpG, cytosine/guanine enriched sites; EZH2, enhancer of zeste homolog 2; GSTP1, glutathione S-transferase Pi 1; HDAC, histone deacetylase; HOXD3, homeobox protein Hox-D3; KDM, lysine demethylase; me, methylation; MGMT, $\mathrm{O}^{6}$-methylguanine-DNA methyltransferase; $\mathrm{PCa}$, prostate cancer; PTGS2, prostaglandin-endoperoxide synthase 2; RARB2, retinoic acid receptor beta 2; RASSF1A, Ras association domain family member 1; SIRT, sirtuin; TGS, tumor suppressor genes 
progression [78]. Assessment of DNA- methylation based panels along with PSA screening demonstrated a high value for prediction and/or recurrence detection in $\mathrm{PCa}$ patients [79]. Adenomatous polyposis coli $(A P C)$ is a common transcriptionally repressed TSG associated with PCa progression [80]. Additionally, well-known specific TSGs and genomic stability regulators such as retinoic acid receptor beta2 (RARß2), cyclin-dependent kinase inhibitor2A $(C D N K 2 A)$, Ras association domain family member1A (RASSF1A), homeobox gene D3 (HOXD3), $\mathrm{O}^{6}$-methylguanine DNA methyltransferase (MGMT), cyclin2 (CCND2), prostaglandin-endoperoxide synthase 2 (PTGS2), and glutathione S-transferase Pi1 (GSTP1) were also commonly silenced by promoter methylation in $\mathrm{PCa}$ (Fig. 2A).

\section{Chromatin remodeling modifiers}

Histone post-translational modifications (PTMs) are enzymatic modifications of proteins. These reactions are written/established by histone methyltransferases (KMTs) and histone acetyltransferases (HATs) and erased/removed by histone demethylases (KDMs) and histone deacetylases (HDACs). Tumor plasticity and epigenetic dynamics may lead to tumor cells' aggressive phenotypes, like those found in CSC markers, including, tumor growth and proliferation, metastasis, and resistance to therapy [81].

\section{Histone methylation}

Deregulation of KMTs and KDMs was observed in PCa cells and was associated with cancer cell proliferation [82]. These changes generally have a pleiotropic effect that can either lead to gene transcription-repression or -activation [72]. The KMT enhancer of zeste homolog 2 (EZH2) is strongly overexpressed in PCa cells, including aggressive NEPC cells, and is generally linked to transcriptional repression through trimethylation of lysine 27 on histone 3 (H3K27me3) [83]. A member of the Jumonji C-domain (JmjC) 2-oxoglutarate-dependent dioxygenase KDM superfamily, JMJD3/UTX/KDM6, that acts as a transcriptional activator is also deregulated in $\mathrm{PCa}$ (Fig. 2C) [84]. This tight balance between methylation and demethylation of histone 3 and the downstream impact in specific pro-tumorigenic or anti-neoplastic gene targets is a major challenge in translational and precision medicine research, meaning that specific epidrugs targeting either EZH2 or KDM6 can elicit antagonistic effects in tumor cells, depending on their context and environment [84]. In PCa samples, H3K27me3 mark was reported to be enriched in several specific promoter regions of TSGs, such as FBXO11, ING3, and RKIP, as well as other tumor regulatory genes [85]. In contrast, other studies found that KDM6 enhanced activity mediating transcriptional activation of specific target genes involved in key PCa carcinogenic pathways, including AR signaling [84]. Moreover, KMTs downregulation, namely SUV39H1 (KMT1A) results in lower levels of another repressive mark, $\mathrm{H} 3 \mathrm{~K} 9 \mathrm{me} 3$, in $\mathrm{PCa}$ cells [86]. Increased expression of several KDMs including LSD1 (KDM1A), a lysine-specific demethylase, and JmjC-KDMs as JMJD1A/KDM3A, JMJD1B/KDM3B, JMJD2A/KDM4A, JMJD2C/KDM4C, JARID1B/KDM5B, and PHF8/KDM7B was also reported in $\mathrm{PCa}$, resulting in higher $\mathrm{PCa}$ proliferation, migration, and invasion (Fig. 2C) [87].

\section{Histone acetylation}

Histone acetylation is another widely studied histone modification in PCa. Unlike histone methylation, acetylation is usually associated with transcriptional activation due to DNA molecule relaxing by histone charge neutralization. Co-activator complex proteins with a conserved HAT domain, such as $\mathrm{p} 300 / \mathrm{CREB}$ binding protein (CBP), play a key role in the progression of AR-dependent $\mathrm{PCa}$ cells through AR acetylation (Fig. 2D) [88]. Hyperacetylation of histone 3 lysine residues 9, 14, and 18 (H3K9ac, H3K14ac, H3K18ac) induces castration-resistant progression in PCa cells via p300 activity [89]. Additionally, higher levels of acetylated histone 4 lysine 16 (H4K16ac) in $\mathrm{PCa}$ cells was reported to induce transcriptional activation of pro-inflammatory genes, such as tumor necrosis factor alpha (TNF- $\alpha$ ) and nuclear factor kappalight-chain-enhancer of activated B cells (NF-KB) [90].

Furthermore, HDACs are a large family of chromatin remodelers comprising four major classes (I, II, III, and IV) regulating both transcription factors and histone deacetylation [81]. Class III HDACs are a particular class of sirtuins (SIRTs) with a $\mathrm{NAD}^{+}$-dependent catalytic activity mechanism, whereas other classes are zincdependent. Histone deacetylation is a common PTM in $\mathrm{PCa}$ generally leading to transcriptional repression of specific genes [81]. HDACs' overexpression, including HDAC1, HDAC2, and HDAC3, was tightly associated with PCa progression and aggressiveness (Fig. 2D) [91]. Specifically, HDAC1 activity induced Yan Yang 1(YY1)mediated repression of XIAP-associated factor 1 (XAF1) in PCa cells [92]. Furthermore, HDAC2 was named a good candidate PCa prognostic biomarker [91]. The combined effect of both mechanisms, such as increased H3K27me3 and decreased H3K9ac, induced tumor suppressor TIMP3 inhibition, in PCa cells [93]. Increased HDAC activity was associated with ERG expression, which inhibits HATs activity in PCa cells [94]. Interestingly, HDAC6 (a class IIb HDAC) regulates AR protein stabilization in CRPC, through Hsp90 transcription factor substrate (Fig. 2D) [95]. Conversely, HDAC4 (a class 
IIa HDAC) an endogenous regulator, binds with AR, inhibiting its activity in AR-dependent PCa cells through SUMOylation, another epigenetic remodeling mechanism [96]. SIRTs are also overexpressed in PCa cells. Specifically, SIRT7 upregulation lead to PCa progression, increased cell migration, and invasion (Fig. 2D) [97]. These findings support the clinical value of using these targets as predictive biomarkers in advanced $\mathrm{PCa}$ patients. Further discussion about available drugs for these targets will be done in the next section of radiosensitizing strategies.

\section{Radiation and epigenetic dynamics interactions}

Although epigenetic regulation has been implicated in cellular radiation response control of $\mathrm{PCa}$ [98], convincing clinical evidence and validation of these findings are lacking. As discussed above, cancer cell death is the major goal in radiation-based therapy. Importantly, targeting DNA repair and cell cycle regulatory pathways might overcome PCa radioresistance [99]. Overall, radiation was demonstrated to induce chromosomal instability, mainly through specific methylation patterns and a wide range of histone PTMs [100]. Epigenomic modifications are involved in cell growth pathways and radioresistant signatures regulation. Concurrently, radiotherapeutic treatment was also found to cause epigenetic changes in PCa cells [101]. Notably, although global DNA hypomethylation has been considered a hallmark of most cancers (by contributing to general genomic instability), this is commonly accompanied by increased DNA methylation levels at specific CpG sites and gene promoters (namely those belonging to tumor suppressor genes), as observed after exposure to IR (Fig. 3A) [102-104]. These changes influenced the recruitment of DSB repair agents, such as $\gamma-\mathrm{H} 2 \mathrm{AX}$ and BRCA1, for an efficient damage response in PC-3, a radioresistant PCa cell line (Fig. 3A) [102]. Additionally, PCSC growth was stimulated after RT exposure through specific epigenetic modulation [7]. Accumulation of H3K36me3 at aldehyde dehydrogenase 1A (ALDH1A1) promoter region, a CSC-related marker,

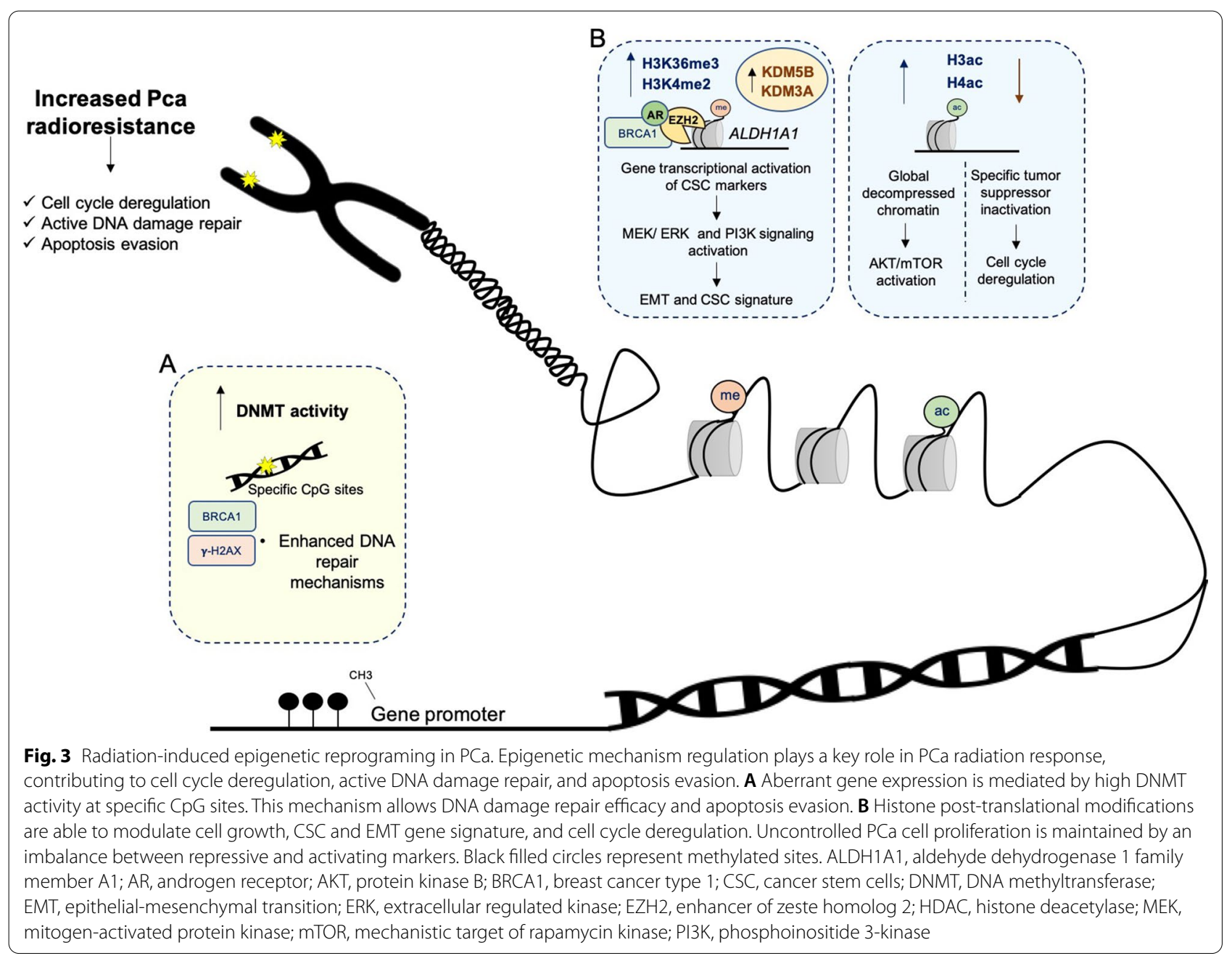


along with EZH2 overexpression, associated with radiation-induced resistance in PCa (Fig. 3B) [7]. Accordingly, enhanced EZH2 activity cooperates with BRCA1, maintaining CSC signature and PCa radioresistance [105]. Furthermore, EZH2 sustained MEK/ERK signaling pathway activation during EMT, allowing PCa proliferation and invasiveness (Fig. 3B) [106].

As previously described, PI3K and androgens are key determinants of $\mathrm{PCa}$ signaling pathways, sustaining tumor growth after cell death-based treatments. Uncontrolled cell cycle proliferation and stimulated growth pathways are determined by epigenetic mechanisms [81]. Hence, increased androgen driven H3K4me2 levels activate PI3K signaling pathway, resulting in CRPC progression (Fig. 3B) [107]. Androgen-mediated effects were previously associated with a relaxed chromatin structure due to higher histone acetylation levels [108]. Both $\mathrm{H} 3$ and $\mathrm{H} 4$ acetylation activate Akt/mTOR, increasing $\mathrm{PCa}$ progression, and therapy resistance (Fig. 3B) [108]. Conversely, increased HDAC activity was linked to specific tumor suppressor inactivation in $\mathrm{PCa}$ (Fig. 3B) [91]. Moreover, several HDAC inhibitors ( $\mathrm{HDACi}$ ) were described as radiosensitizers, affecting both DSB repair machinery and cell cycle controlling pathways [109]. In terms of histone methylation, inactive KDM5D induced aberrant and faster cell division, activating DDR-related pathways in $\mathrm{PCa}$, such as enhanced ATR kinase activity, conferring a more aggressive phenotype (Fig. 3B) [110]. Conversely, KDM5B overexpression led to a radioresistant phenotype in non-small cell lung cancer and PCa cell lines (Fig. 3B) [111]. Herein, clinical samples of non-small cell lung cancer showed lower RT response rates when higher levels of KDM5B were detected [111]. KDM3A, with substrate selectivity for H3K9me1/2, also induced aberrant DDR activation in radioresistant $\mathrm{PCa}$ [112]. Reversion of these epigenetic changes affected the recruitment of DSB repair molecules such as $\gamma-\mathrm{H} 2 \mathrm{AX}$ and ATM, increasing tumor radiosensitivity [111]. Furthermore, a key regulatory cell cycle component, cyclin D2, is a candidate target of SMYD3 (KMT that specifically catalyzes transcriptional suppressive trimethylation of H4K20) [113]. This interplay, leads to deregulated cell cycle pathways and aberrant mitosis, resulting in uncontrolled PCa cell progression [113].

\section{Strategies for radiosensitizing tumor cells with well-known epigenetic targeting drugs}

The development of epigenetic compounds with radiosensitizing properties rationalizes the use of these drugs in a clinical context. Nevertheless, the demonstration of solid effectiveness of epigenetic-based radiosensitization in PCa is still lacking. Although a wide range of HDACi tested in several cancer models including PCa showed impressive anticancer properties, the specific effect of these epidrugs in cells after IR exposure remains elusive and do not progress after pre-clinical level. To date, only few clinical trials investigated the radiosensitizing effect of these inhibitors are summarized in Table 1. Remarkably, the major drawback of these studies are the toxicity effects. Additionally, larger randomized trials to corroborate the tolerability to the drugs and to evaluate the efficacy in the local control are needed. In fact, most of these clinical trials included a reduced number of participants who had completed the protocol. Furthermore, especially in relation to $\mathrm{HDACi}$, to improve their current adoption into the clinical practice, it would be pertinent and helpful the development of newer, more specific HDACi or other epidrugs, as discussed previous. These inhibitors only target global histone acetylation and not specific lysine sites.

Vorinostat, an FDA-approved HDACi (also known as SAHA) displays a potential radiosensitizer effect in several cancers (Fig. 4 and Additional file 1). Specifically, vorinostat improved radiosensitivity in three $\mathrm{PCa}$ cell lines with different radiation response patterns, both in normoxia and hypoxia conditions [114]. The radiosensitizer use of vorinostat decreased cell survival fraction and significantly increased G2/M cell fraction, along with specific HIF-1 $\alpha$ and TP53 target downregulation [114]. Several clinical trials have reported considerable benefits of vorinostat in many cancer types subjected to IR (Table 1). Valproic acid (VPA), a common anti-epileptic drug, also a well-known HDACi, radiosensitize several cancers undergoing fractionated RT (Fig. 4 and Additional file 1). Low VPA concentrations $(50 \mu \mathrm{M})$ sensitized PCa cells to IR through p53 acetylation stabilization and enhanced apoptosis (Fig. 4 and Additional file 1). Indeed, several reported studies corroborate these findings in other cancers (Fig. 4 and Additional file 1, Table 1). Trichostatin A (TSA), another HDACi, sensitized a PCSCs radioresistant fraction and depicted similar effect in other cancer models, showing increased radiationinduced DNA damage (Fig. 4). In the same vein, panobinostat (LBH-589), pan-HDACi, was able to increase $\mathrm{PCa}$ radiosensitivity as well as in other cancer types (Fig. 4 and Additional file 1, Table 1). The radiosensitizing effect of entinostat (MS-275) was studied in vitro in PCa and glioma cells (Fig. 4 and Additional file 1). Herein, along with irradiation, entinostat increased tumor cell apoptosis, as well as, radiosensitivity (Fig. 4 and Additional file 1). Although other well-known HDACi's, such as FK228, CBHA, sodium butyrate, TMP195, and mocetinostat, were reported to exhibit a potential radiosensitizing effect by affecting DNA repair pathways (HR and $\mathrm{NHEJ}$ ) in several malignancies, studies are lacking for PCa (Fig. 4 and Additional file 1). 
Table 1 Epigenetic clinical trials with well-known epidrugs to overcome cancer radioresistance

\begin{tabular}{|c|c|c|c|c|c|c|c|c|c|}
\hline Drug & $\begin{array}{l}\text { Clinical } \\
\text { trials }\end{array}$ & Target & $\begin{array}{l}\text { Cancer } \\
\text { type }\end{array}$ & Patients & Doses & OS rates & $\begin{array}{l}\text { Year of } \\
\text { publication }\end{array}$ & References & Study ID \\
\hline SAHA & Phase I & $\mathrm{HDACi}$ & $\begin{array}{l}\text { Brain } \\
\text { metas- } \\
\text { tasis }\end{array}$ & $\begin{array}{l}4 \text { com- } \\
\text { pleted } \\
\text { study } \\
\text { protocol }\end{array}$ & $\begin{array}{l}400 \mathrm{mg} / \\
\text { day with } \\
37.5 \mathrm{~Gy} \\
(2.5 \mathrm{~Gy} / \\
\text { fr.) over } \\
5 \text { weeks }\end{array}$ & 36 weeks & 2014 & [119] & NCT01600742 \\
\hline SAHA & Phase I & $\mathrm{HDACi}$ & $\begin{array}{l}\text { NSCLC } \\
\text { brain } \\
\text { metas- } \\
\text { tasis }\end{array}$ & $\begin{array}{l}12 \text { com- } \\
\text { pleted } \\
\text { study } \\
\text { protocol }\end{array}$ & $\begin{array}{l}\text { 200-400 mg/ } \\
\text { day for } \\
14 \text { days } \\
\text { with SD } \\
\text { of SRS at } \\
\text { day } 3\end{array}$ & 13 months & 2017 & [120] & NCT00946673 \\
\hline SAHA & Phase I/II & $\mathrm{HDACi}$ & $\begin{array}{l}\text { Glioblas- } \\
\text { toma }\end{array}$ & $\begin{array}{l}\text { Phase I: } 15 \\
\text { Phase II: } \\
107\end{array}$ & $\begin{array}{l}300 \text { or } \\
400 \mathrm{mg} / \\
\text { day } \\
\text { with Std } \\
\text { TMZ+RT }\end{array}$ & $\begin{array}{l}55.1 \% \text {, } \\
15 \text { months } \\
\text { FU }\end{array}$ & 2018 & [121] & NCT00731731 \\
\hline SAHA & Phase I & $\mathrm{HDACi}$ & $\begin{array}{l}\text { Advanced } \\
\text { head } \\
\text { and neck } \\
\text { SCC }\end{array}$ & $\begin{array}{l}26 \text { com- } \\
\text { pleted } \\
\text { study } \\
\text { protocol }\end{array}$ & $\begin{array}{l}\text { 100-400 mg, } \\
3 \times \text { weekly } \\
\text { with } \\
\text { concurrent } \\
\text { CRT }\end{array}$ & $\begin{array}{l}96.2 \% \text { CR at } \\
33.8 \text { months } \\
\text { FU }\end{array}$ & 2019 & [122] & NCT01064921 \\
\hline VPA & Phase II & $\mathrm{HDACi}$ & $\begin{array}{l}\text { Glioblas- } \\
\text { toma }\end{array}$ & $\begin{array}{l}37 \text { com- } \\
\text { pleted } \\
\text { study } \\
\text { protocol }\end{array}$ & $\begin{array}{l}25 \mathrm{mg} / \\
\mathrm{kg} \text { oral } \\
\text { divided } \\
\text { in } 2 \mathrm{dd} \\
\text { concurrent } \\
\text { with RT } \\
\text { and TMZ }\end{array}$ & $\begin{array}{l}97 \%, 86 \% \\
\text { and } 65 \% \text { at } \\
6,12 \text {, and } \\
24 \text { months } \\
\text { FU, respec- } \\
\text { tively }\end{array}$ & 2015 & [123] & NIHMS686154 \\
\hline $\begin{array}{l}\text { VPA + Hydrala- } \\
\text { zine }\end{array}$ & Phase III & $\mathrm{HDACi}+\mathrm{DNMTi}$ & $\begin{array}{l}\text { Stage III } \\
\text { cervical } \\
\text { cancer }\end{array}$ & $\begin{array}{l}18 \text { com- } \\
\text { pleted } \\
\text { study } \\
\text { protocol }\end{array}$ & $\begin{array}{l}182 \mathrm{mg} \text { or } \\
83 \mathrm{mg} \text { of } \\
\text { hydrala- } \\
\text { zine and } \\
30 \mathrm{mg} / \mathrm{kg} \\
\text { VPA plus } \\
\text { TCD of } \\
85 \mathrm{~Gy}\end{array}$ & NS & 2010 & [124] & NCT02446652 \\
\hline LBH-589 & Phase I & $\mathrm{HDACi}$ & $\begin{array}{l}\text { Stage III } \\
\text { NSCLC }\end{array}$ & 9 with $\mathrm{pRT}$ & $\begin{array}{l}\text { 20, } 30,45 \mathrm{mg} \\
\text { twice/ } \\
\text { week, with } \\
\text { pRT or } \\
\text { rCRT }\end{array}$ & 9 months & 2015 & [125] & NA \\
\hline LBH-589 & Phase I & $\mathrm{HDACi}$ & $\begin{array}{l}\text { High } \\
\text { grade } \\
\text { gliomas }\end{array}$ & $\begin{array}{l}12 \text { com- } \\
\text { pleted } \\
\text { study } \\
\text { protocol }\end{array}$ & $\begin{array}{l}\text { 10, 20, } \\
30 \mathrm{mg} / \\
\text { day, with } \\
30-35 \mathrm{~Gy} \\
(10 \mathrm{fr} .)\end{array}$ & $\begin{array}{l}\text { 7.8; } 6.1 \text {, and } \\
16.1 \text { for each } \\
\text { drug con- } \\
\text { centration, } \\
\text { respectively }\end{array}$ & 2016 & [126] & NCT01324635 \\
\hline LBH-589 & Phase I & $\mathrm{HDACi}$ & $\begin{array}{l}\text { HNC, PCa } \\
\text { and } \\
\text { Esopha- } \\
\text { geal } \\
\text { cancer }\end{array}$ & $\begin{array}{l}7 \text { com- } \\
\text { pleted } \\
\text { study } \\
\text { protocol }\end{array}$ & NS & NS & 2017 & NP & NCT00670553 \\
\hline
\end{tabular}

CR, complete response; CRT, chemoradiotherapy; DNMTi, DNA methyltransferase inhibitors; FU, follow-up; Fr., fraction; HDACi, histone deacetylase inhibitors; HNC, Head and neck cancer; NS, not specified; OS, overall survival; RT, radiotherapy; TMZ, temozolomide; VPA, Valproic acid; pRT, palliative radiotherapy; PCa, prostate cancer; NA, not available; NP, not published; NS, not specified; NSCLC, non-small cell lung cancer; SCC, squamous cell carcinoma; SD, standard dose; SRS, stereotactic radiosurgery

DNA hypomethylating agents, DNMT inhibitors (DNMTi), also play a role in tumor radiosensitization. Specifically, the use of HDACi in combination with
DNMTi showed a cumulative effect on cancer radiosensitization (Table 1, reporting combinatorial radiosensitization clinical trials in PCa and other cancers). 


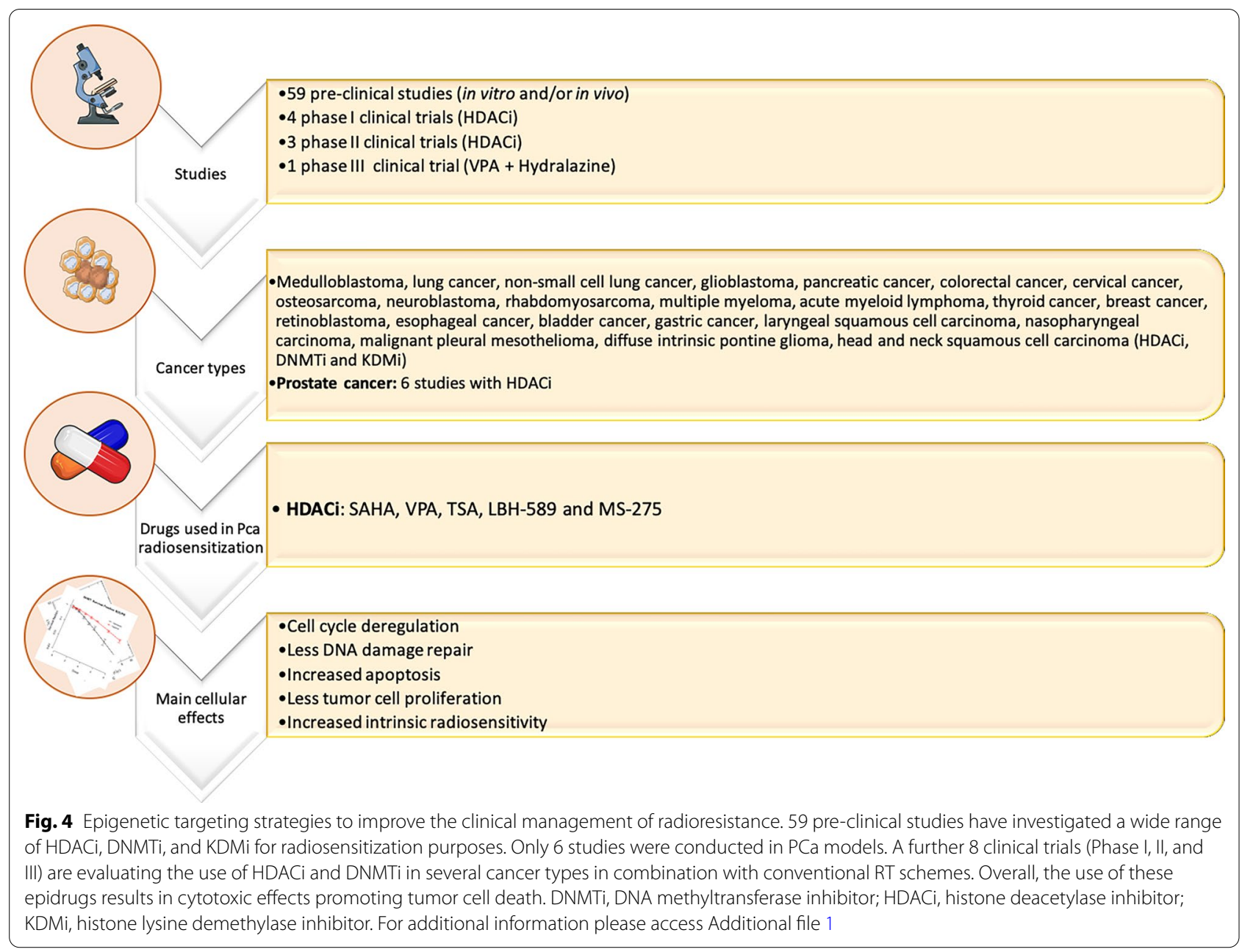

5-aza-2'-deoxycytidine (DAC) is the most commonly studied DNMTi (Fig. 4 and Additional file 1). Nonetheless, no reports are still available about $\mathrm{PCa}$ radiosensitization by these epidrugs (Fig. 4 and Additional file 1). Concerning histone methylation, JmjC-KDMs and LDS/ KDM1A inhibitors are two well-known epigenetic drugs, with a limited number of studies about cancer radiosensitization. GSK-J4 is the most studied JmjC-KDM inhibitor, with KDM6/UTX specificity and cancer radiosensitivity effect (Fig. 4 and Additional file 1). Another JmjC-KDM inhibitor with higher specificity for KDM5 subfamily inhibition, JIB-04, was able to enhanced radiation response of lung squamous cell carcinoma cells [111]. Despite extensive knowledge of KDMs' implication in hypoxia and tumor aggressiveness, as discussed in fifth section, few recent pre-clinical studies provided evidence that KDM activity inhibition may associate with tumor radiosensitization. Remarkably, LSD1/KDM1A has been highlighted as an important chromatin and gene transcriptional modulator in PCa [115]. LSD1 inhibitors are emerging as successful drugs with important role in PCa progression blockage, as well as, CRPC growth suppression [115]. However, there are a lack of approved inhibitors in radiation field with clinical validation. Of note, previous in vitro reports shown LSD1 transient recruitment to DNA damage allowing the activation of $\mathrm{HR}$ DNA repair machinery, such as 53BP1 and BRCA1 [116]. Herein, mechanistic studies with LSD1 knockdown significantly enhanced radiosensitivity [116]. Hence, LSD1 seems to be an interesting target to use in future as a tumor radiosensitizer, also for PCa. Additionally, BRD4, a bromodomain family-member with essential role as chromatin remodeler has been reported as a synergic interactor of LSD1 in CRPC [117]. Furthermore, BRD4 has a critical role for NHEJ DNA damage repair pathway and a low prognostic value for PCa patients submitted to RT [118]. In fact, according to the aforementioned clinical trials using epigenetic drugs, most of the inhibitors used are broad range effectors. The lack of specific targeting drugs is a critical drawback in the research field. 
Overall, further insights in the discovery of promising targetable epigenetic enzymes are urgently needed. For instance, as previously discussed in fifth section, KDM3A [112] and SMYD3 [113] were reported with a critical role as DNA damage and cell cycle mediators in PCa. The expression of these enzymes is commonly associated with poor PCa prognosis. However, until now there are no further validation with specific targeting epigenetic drugs.

\section{Conclusions and future perspectives}

Although PCa mostly constitutes a rather indolent malignancy, in a non-negligible percentage of cases can progress to highly aggressive disease. Advancements in translational research and innovative precision medicine techniques are urgently needed to determine the optimal clinical management based on intrinsic tumor biology. As many PCa patients are primarily treated with standard fractionated RT schemes, the development of novel adjuvant targeted strategies is imperative to overcome high recurrence rates of $20-40 \%$ in this subgroup of $\mathrm{PCa}$ patients. Epigenetic targeting might be the key to improving and extending survival of PCa patients. Indeed, epigenetically-inducible changes in DNA repair pathways and cell cycle play a critical role in response to IR. Cellular dynamics at epigenetic level led to overall tumor aggressiveness, increasing cell proliferation, invasion, and migration. Thus, the identification of specific key epigenetic targets and the use of epidrugs, such as inhibitors of DNMTs, HDACs, or KDMs, might radiosensitize tumor cells, increasing patients' response to therapy and overall survival. Nevertheless, other studies are needed to further support these epidrugs as a novel treatment that should be used in combination with standard RT to improve PCa patients' outcome.

\footnotetext{
Abbreviations

RT: Radiotherapy; PCa: Prostate cancer; PSA: Prostate specific antigen; EBRT: External beam radiation therapy; HRPC: High risk prostate cancer; IR: lonizing radiation; PCSC: Prostate cancer stem cells; NED: Neuroendocrine differentiation; IMRT: Intensity modulated radiotherapy; VMAT: Volumetric-modulated arc therapy; IGRT: Image-guided radiotherapy; bDFS: Biochemical disease-free survival; ADT: Androgen deprivation therapy; DSB: Double strand breaks; DDR: DNA damage repair; $y$-ATM: Autophosphorylated ataxia telangiectasia mutated; BRCA: Breast cancer gene 1/2; PARP: Poly(ADP-ribose) polymerase 1; BER: Base excision repair; NHEJ: Non homologous end-joining; HR: Homologous recombination; CRPC: Castration resistant prostate cancer; EMT: Epithelial mesenchymal transition; HIF: Hypoxia-inducible factor; VEGF: Vascular endothelial growth factor; CAIX: Carbonic anhydrase IX; GLUT-1: Glucose transporter 1; ROS: Reactive oxygen species; PTEN: Phosphatidylinositol 3,4,5-triphosphate 3-phosphatase; CSC: Cancer stem cells; NEPC: Neuroendocrine prostate cancer; IncRNA: Long non-coding RNA; miRNA: Micro RNA; RMI2: RecQ-mediated genome instability 2; TOPBP1: DNA topoisomerase II binding protein 1; DNMT: DNA methyltransferase; LINE-1: Long interspersed nuclear element-1; TET: Ten-eleven translocation; APC: Adenomatous polyposis coli; TSG: Tumor supressor gene; RAR $\beta 2$ : Retinoic acid receptor beta2; RASSF1A: Ras association domain family member1 $A_{\text {; }}$ CDNK2A: Cyclin-dependent kinase inhibitor2A; HOXD3: Homeobox gene
}

D3; MGMT: $0^{6}$-methylguanine DNA methyltransferase; PTGS2: Prostaglandinendoperoxide synthase 2; CCND2: Cyclin2; GSTP1: Glutathione S-transferase Pi1; KMT: Lysine methyltransferase; KDM: Lysine demethylase; EZH2: Enhancer of zeste homolog 2; ImjC: Jumonji c domain; CBP: P300/CREB binding protein; HAT: Histone acetyltransferase; TNF: Tumor necrosis factor; NF-kB: Nuclear factor kappa-light-chain-enhancer of activated B cells; SIRT: Sirtuins; XAF1: XIAP-associated factor 1; YY1: Yan Yang 1; PTM: Post translational modifications; IR: lonizing radiation; HDACi: HDAC inhibitors; DNMTi: DNMT inhibitors.

\section{Supplementary Information}

The online version contains supplementary material available at https://doi. org/10.1186/s13148-021-01111-8.

Additional file 1. Complementary pre-clinical studies for tumor radiosensitization.

\section{Authors' contributions}

CM-S and RB conceptualized the paper. CM-S collected, analysed the information and elaborated the figures. CM-S, RB, FC, SC, CJ and LA drafted and revised the paper. All authors read and approved the final manuscript.

\section{Funding}

This work was supported by AIRC-17217; Campania Regional Government Technology Platform Lotta alle Patologie Oncologiche: iCUREB21C17000030007; "Epigenetic Hallmarks of Multiple Sclerosis" (acronym EpiMS) (id:415, Merit Ranking Area ERC LS) in VALERE 2019 Program; V:ALERE 2020 - Progetto competitivo "CIRCE" in risposta al bando D.R. n. 138 del 17/02/2020 Program; Campania Regional Government FASE2: IDEAL:Identificazione e caratterizzazione di nuovi approcci terapeutici contro il cancro CUP B63D18000560007; MIUR, Proof of Concept-EPICUREPOC01_00043-

B64I19000290008; P.O.R. CAMPANIA FSE 2014/2020 ASSE III-B27D18001070006.

Availability of data and materials

Not applicable.

\section{Declarations}

Ethics approval and consent to participate

Not applicable.

\section{Consent for publication}

Not applicable.

\section{Competing interests}

The authors have declared no conflict of interest.

\section{Author details}

'Department of Precision Medicine, University of Campania "Luigi Vanvitelli", Vico L. De Crecchio 7, 80138 Naplei, Italy. ${ }^{2}$ Cancer Biology and Epigenetics Group, Research Center at Portuguese Oncology Institute of Porto, F Bdg, 1st Floor, Rua Dr. António Bernardino de Almeida, 4200-072 Porto, Portugal. ${ }^{3}$ Department of Pathology and Molecular Immunology at School of Medicine and Biomedical Sciences, University of Porto (ICBAS-UP), Porto, Portugal.

Received: 6 March 2021 Accepted: 2 June 2021

Published online: 08 June 2021

\footnotetext{
References

1. Bray F, Ferlay J, Soerjomataram I, Siegel RL, Torre LA, Jemal A. Global cancer statistics 2018: GLOBOCAN estimates of incidence and mortality worldwide for 36 cancers in 185 countries. CA Cancer J Clin. 2018:68:394-424.

2. Sung H, Ferlay J, Siegel RL, Laversanne M, Soerjomataram I, Jemal A, et al. Global cancer statistics 2020: GLOBOCAN estimates of incidence
} 
and mortality worldwide for 36 cancers in 185 countries. CA Cancer J Clin. 2021;71:209-49.

3. Morgan SC, Hoffman K, Loblaw DA, Buyyounouski MK, Patton C, Barocas D, et al. Hypofractionated radiation therapy for localized prostate cancer: executive summary of an ASTRO, ASCO, and AUA evidencebased guideline. Pract Radiat Oncol. 2018;8(6):354-60.

4. Khuntia D, Reddy CA, Mahadevan A, Klein EA, Kupelian PA. Recurrencefree survival rates after external-beam radiotherapy for patients with clinical T1-T3 prostate carcinoma in the prostate-specific antigen era: what should we expect? Cancer. 2004;100(6):1283-92.

5. Nickoloff JA, Boss MK, Allen CP, LaRue SM. Translational research in radiation-induced DNA damage signaling and repair. Transl Cancer Res. 2017:6(Suppl 5):S875-91.

6. McDermott N, Meunier A, Mooney B, Nortey G, Hernandez C, Hurley $S$, et al. Fractionated radiation exposure amplifies the radioresistant nature of prostate cancer cells. Sci Rep. 2016;6:34796.

7. Peitzsch C, Cojoc M, Hein L, Kurth I, Mäbert K, Trautmann F, et al. An epigenetic reprogramming strategy to resensitize radioresistant prostate cancer cells. Cancer Res. 2016;76(9):2637-51.

8. Fowler JF. The radiobiology of prostate cancer including new aspects of fractionated radiotherapy. Acta Oncol. 2005;44(3):265-76.

9. Dasu A, Toma-Dasu I. Prostate alpha/beta revisited - an analysis of clinical results from 14168 patients. Acta Oncol. 2012;51(8):963-74.

10. Cho LC, Timmerman R, Kavanagh B. Hypofractionated external-beam radiotherapy for prostate cancer. Prostate Cancer. 2013;2013:103547.

11. Chow JCL, Jiang R. Dose-volume and radiobiological dependence on the calculation grid size in prostate VMAT planning. Med Dosim. 2018;43(4):383-9.

12. Alongi F, Fiorentino A, De Bari B. SBRT and extreme hypofractionation: A new era in prostate cancer treatments? Rep Pract Oncol Radiother. 2015;20(6):411-6

13. De Bari B, Fiorentino A, Arcangeli S, Franco P, D'Angelillo RM, Alongi F. From radiobiology to technology: what is changing in radiotherapy for prostate cancer. Expert Rev Anticancer Ther. 2014;14(5):553-64.

14. Zelefsky MJ, Pei X, Chou JF, Schechter M, Kollmeier M, Cox B, et al. Dose escalation for prostate cancer radiotherapy: predictors of long-term biochemical tumor control and distant metastases-free survival outcomes. Eur Urol. 2011;60(6):1133-9.

15. Carrie C, Magné N, Burban-Provost P, Sargos P, Latorzeff I, Lagrange $J \mathrm{~L}$, et al. Short-term androgen deprivation therapy combined with radiotherapy as salvage treatment after radical prostatectomy for prostate cancer (GETUG-AFU 16): a 112-month follow-up of a phase 3, randomised trial. Lancet Oncol. 2019;20(12):1740-9.

16. Vale CL, Burdett S, Rydzewska LHM, Albiges L, Clarke NW, Fisher D, et al. Addition of docetaxel or bisphosphonates to standard of care in men with localised or metastatic, hormone-sensitive prostate cancer: a systematic review and meta-analyses of aggregate data. Lancet Oncol. 2016;17(2):243-56.

17. Pajonk F, Vlashi E, McBride WH. Radiation resistance of cancer stem cells: the 4 R's of radiobiology revisited. Stem Cells. 2010;28(4):639-48.

18. Ray KJ, Sibson NR, Kiltie AE. Treatment of breast and prostate cancer by hypofractionated radiotherapy: potential risks and benefits. Clin Oncol (R Coll Radiol). 2015;27(7):420-6.

19. Guo W, Sun YC, Bi JQ, He XY, Xiao L. Hypofractionated radiotherapy versus conventional radiotherapy in patients with intermediate- to high-risk localized prostate cancer: a meta-analysis of randomized controlled trials. BMC Cancer. 2019;19(1):1063.

20. Mansour WY, Tennstedt P, Volquardsen J, Oing C, Kluth M, Hube-Magg C, et al. Loss of PTEN-assisted G2/M checkpoint impedes homologous recombination repair and enhances radio-curability and PARP inhibitor treatment response in prostate cancer. Sci Rep. 2018;8(1):3947.

21. De Felice F, Tombolini V, Marampon F, Musella A, Marchetti C. Defective DNA repair mechanisms in prostate cancer: impact of olaparib. Drug Des Devel Ther. 2017;11:547-52.

22. Alberti C. Prostate cancer: radioresistance molecular target-related markers and foreseeable modalities of radiosensitization. Eur Rev Med Pharmacol Sci. 2014;18(16):2275-82.

23. Warner EW, Yip SM, Chi KN, Wyatt AW. DNA repair defects in prostate cancer: impact for screening, prognostication and treatment. BJU Int. 2019;123(5):769-76.
24. Frank $\mathrm{S}$, Nelson P, Vasioukhin V. Recent advances in prostate cancer research: large-scale genomic analyses reveal novel driver mutations and DNA repair defects. F1000Res. 2018;7.

25. Maranto C, Udhane V, Hoang DT, Gu L, Alexeev V, Malas K, et al. STAT5A/B blockade sensitizes prostate cancer to radiation through inhibition of RAD51 and DNA repair. Clin Cancer Res. 2018;24(8):1917-31.

26. Casimiro MC, Di Sante G, Ju X, Li Z, Chen K, Crosariol M, et al. Cyclin D1 promotes androgen-dependent DNA damage repair in prostate cancer cells. Cancer Res. 2016;76(2):329-38.

27. Chang L, Graham PH, Hao J, Ni J, Bucci J, Cozzi PJ, et al. Acquisition of epithelial-mesenchymal transition and cancer stem cell phenotypes is associated with activation of the PI3K/Akt/mTOR pathway in prostate cancer radioresistance. Cell Death Dis. 2013:4:e875.

28. Gravina GL, Marampon F, Sherris D, Vittorini F, Di Cesare E, Tombolini V, et al. Torc1/Torc2 inhibitor, Palomid 529, enhances radiation response modulating CRM1-mediated survivin function and delaying DNA repair in prostate cancer models. Prostate. 2014;74(8):852-68.

29. Chen Y, Wang Y, Yu Y, Xu L, Zhang Y, Yu S, et al. Transcription factor HBP1 enhances radiosensitivity by inducing apoptosis in prostate cancer cell lines. Anal Cell Pathol (Amst). 2016;2016:7015659.

30. Pawlik TM, Keyomarsi K. Role of cell cycle in mediating sensitivity to radiotherapy. Int J Radiat Oncol Biol Phys. 2004;59(4):928-42.

31. Keam SP, Caramia F, Gamell C, Paul PJ, Arnau GM, Neeson PJ, et al. The transcriptional landscape of radiation-treated human prostate cancer: analysis of a prospective tissue cohort. Int J Radiat Oncol Biol Phys. 2018;100(1):188-98.

32. Nguyen KH, Hachem P, Khor LY, Salem N, Hunt KK, Calkins PR, et al. Adenoviral-E2F-1 radiosensitizes p53wild-type and p53null human prostate cancer cells. Int J Radiat Oncol Biol Phys. 2005;63(1):238-46.

33. Udayakumar TS, Hachem P, Ahmed MM, Agrawal S, Pollack A. Antisense MDM2 enhances E2F1-induced apoptosis and the combination sensitizes androgen-sensitive [corrected] and androgen-insensitive [corrected] prostate cancer cells to radiation. Mol Cancer Res. 2008;6(11):1742-54.

34. Kamel D, Gray C, Walia JS, Kumar V. PARP inhibitor drugs in the treatment of breast, ovarian, prostate and pancreatic cancers: an update of clinical trials. Curr Drug Targets. 2018;19(1):21-37.

35. Han S, Brenner JC, Sabolch A, Jackson W, Speers C, Wilder-Romans $\mathrm{K}$, et al. Targeted radiosensitization of ETS fusion-positive prostate cancer through PARP1 inhibition. Neoplasia. 2013;15(10):1207-17.

36. van de Ven AL, Tangutoori S, Baldwin P, Qiao J, Gharagouzloo C, Seitzer $\mathrm{N}$, et al. Nanoformulation of olaparib amplifies PARP inhibition and sensitizes PTEN/TP53-deficient prostate cancer to radiation. Mol Cancer Ther. 2017;16(7):1279-89.

37. Oing C, Tennstedt P, Simon R, Volquardsen J, Borgmann K, Bokemeyer C, et al. BCL2-overexpressing prostate cancer cells rely on PARP1dependent end-joining and are sensitive to combined PARP inhibitor and radiation therapy. Cancer Lett. 2018:423:60-70.

38. Barreto-Andrade JC, Efimova EV, Mauceri HJ, Beckett MA, Sutton HG, Darga TE, et al. Response of human prostate cancer cells and tumors to combining PARP inhibition with ionizing radiation. Mol Cancer Ther. 2011;10(7):1185-93.

39. Gani C, Coackley C, Kumareswaran R, Schütze C, Krause M, Zafarana $G$, et al. In vivo studies of the PARP inhibitor, AZD-2281, in combination with fractionated radiotherapy: An exploration of the therapeutic ratio. Radiother Oncol. 2015;116(3):486-94.

40. Hennessey D, Martin LM, Atzberger A, Lynch TH, Hollywood D, Marignol L. Exposure to hypoxia following irradiation increases radioresistance in prostate cancer cells. Urol Oncol. 2013;31(7):1106-16.

41. Horsman MR, Overgaard J. The impact of hypoxia and its modification of the outcome of radiotherapy. J Radiat Res. 2016;57(Suppl 1):i90-8.

42. Nahum AE, Movsas B, Horwitz EM, Stobbe CC, Chapman JD. Incorporating clinical measurements of hypoxia into tumor local control modeling of prostate cancer: implications for the alpha/beta ratio. Int J Radiat Oncol Biol Phys. 2003;57(2):391-401.

43. Carlson DJ, Keall PJ, Loo BW Jr, Chen ZJ, Brown JM. Hypofractionation results in reduced tumor cell kill compared to conventional fractionation for tumors with regions of hypoxia. Int J Radiat Oncol Biol Phys. 2011;79(4):1188-95. 
44. Fang J, Xia C, Cao ZX, Zheng JZ, Reed E, Jiang BH. Apigenin inhibits VEGF and HIF-1 expression via PI3K/AKT/p70S6K1 and HDM2/p53 pathways. FASEB J. 2005;19(3):342-53.

45. Meng AX, Jalali F, Cuddihy A, Chan N, Bindra RS, Glazer PM, et al. Hypoxia down-regulates DNA double strand break repair gene expression in prostate cancer cells. Radiother Oncol. 2005;76(2):168-76.

46. Chan N, Milosevic M, Bristow RG. Tumor hypoxia, DNA repair and prostate cancer progression: new targets and new therapies. Future Oncol. 2007:3(3):329-41.

47. Bindra RS, Crosby ME, Glazer PM. Regulation of DNA repair in hypoxic cancer cells. Cancer Metastasis Rev. 2007;26(2):249-60.

48. Kim W, Lee S, Seo D, Kim D, Kim K, Kim E, et al. Cellular stress responses in radiotherapy. Cells. 2019:8(9):1105.

49. Jayakumar S, Kunwar A, Sandur SK, Pandey BN, Chaubey RC. Differential response of DU145 and $\mathrm{PC} 3$ prostate cancer cells to ionizing radiation: role of reactive oxygen species, GSH and Nrf2 in radiosensitivity. Biochim Biophys Acta. 2014;1840(1):485-94

50. Bhandari V, Hoey C, Liu LY, Lalonde E, Ray J, Livingstone J, et al. Molecular landmarks of tumor hypoxia across cancer types. Nat Genet. 2019;51(2):308-18.

51. Marignol L, Rivera-Figueroa K, Lynch T, Hollywood D. Hypoxia, notch signalling, and prostate cancer. Nat Rev Urol. 2013;10(7):405-13.

52. Cho YM, Kim YS, Kang MJ, Farrar WL, Hurt EM. Long-term recovery of irradiated prostate cancer increases cancer stem cells. Prostate. 2012;72(16):1746-56.

53. Ma Y, Liang D, Liu J, Axcrona K, Kvalheim G, Stokke T, et al. Prostate cancer cell lines under hypoxia exhibit greater stem-like properties. PLoS ONE. 2011;6(12):e29170

54. Civenni G, Albino D, Shinde D, Vázquez R, Merulla J, Kokanovic A, et al. Transcriptional reprogramming and novel therapeutic approaches for targeting prostate cancer stem cells. Front Oncol. 2019:9:385.

55. Kim YS, Kang MJ, Cho YM. Low production of reactive oxygen species and high DNA repair: mechanism of radioresistance of prostate cancer stem cells. Anticancer Res. 2013;33(10):4469-74.

56. Mimeault M, Batra SK. Hypoxia-inducing factors as master regulators of stemness properties and altered metabolism of cancer- and metastasisinitiating cells. J Cell Mol Med. 2013;17(1):30-54.

57. Kyjacova L, Hubackova S, Krejcikova K, Strauss R, Hanzlikova H, Dzijak $\mathrm{R}$, et al. Radiotherapy-induced plasticity of prostate cancer mobilizes stem-like non-adherent, Erk signaling-dependent cells. Cell Death Differ. 2015;22(6):898-911.

58. Wang X, Ma Z, Xiao Z, Liu H, Dou Z, Feng X, et al. Chk1 knockdown confers radiosensitization in prostate cancer stem cells. Oncol Rep. 2012;28(6):2247-54

59. Thompson TC, Liu B, Li L. N-MYC regulation of DNA damage response in neuroendocrine prostate cancer: mechanistic insight and novel combination therapy approaches. Oncoscience. 2018:5(11-12):273-5.

60. Krauss DJ, Hayek S, Amin M, Ye H, Kestin LL, Zadora S, et al. Prognostic significance of neuroendocrine differentiation in patients with Gleason score 8-10 prostate cancer treated with primary radiotherapy. Int J Radiat Oncol Biol Phys. 2011;81(3):e119-25.

61. Patel GK, Chugh N, Tripathi M. Neuroendocrine differentiation of prostate cancer-an intriguing example of tumor evolution at play. Cancers. 2019;11(10):1405.

62. Gupta K, Gupta S. Neuroendocrine differentiation in prostate cancer: key epigenetic players. Transl Cancer Res. 2017;6(Suppl 1):S104-8.

63. Conteduca V, Oromendia C, Eng KW, Bareja R, Sigouros M, Molina A, et al. Clinical features of neuroendocrine prostate cancer. Eur J Cancer. 2019;121:7-18.

64. Bluemn EG, Coleman IM, Lucas JM, Coleman RT, Hernandez-Lopez S, Tharakan $\mathrm{R}$, et al. Androgen receptor pathway-independent prostate cancer is sustained through FGF signaling. Cancer Cell. 2017;32(4):47489.e6.

65. Hu CD, Choo R, Huang J. Neuroendocrine differentiation in prostate cancer: a mechanism of radioresistance and treatment failure. Front Oncol. 2015:5:90.

66. Deng X, Liu H, Huang J, Cheng L, Keller ET, Parsons SJ, et al. lonizing radiation induces prostate cancer neuroendocrine differentiation through interplay of CREB and ATF2: implications for disease progression. Cancer Res. 2008;68(23):9663-70.
67. Suarez CD, Deng X, Hu CD. Targeting CREB inhibits radiation-induced neuroendocrine differentiation and increases radiation-induced cell death in prostate cancer cells. Am J Cancer Res. 2014:4(6):850-61.

68. Huang $Y H$, Zhang YQ, Huang JT. Neuroendocrine cells of prostate cancer: biologic functions and molecular mechanisms. Asian J Androl. 2019;21(3):291-5.

69. Soundararajan R, Paranjape AN, Maity S, Aparicio A, Mani SA. EMT, stemness and tumor plasticity in aggressive variant neuroendocrine prostate cancers. Biochim Biophys Acta Rev Cancer. 2018;1870(2):229-38.

70. Schulz A, Meyer F, Dubrovska A, Borgmann K. Cancer stem cells and radioresistance: DNA repair and beyond. Cancers (Basel). 2019;11(6):862

71. Saga R, Matsuya Y, Takahashi R, Hasegawa K, Date H, Hosokawa Y. Analysis of the high-dose-range radioresistance of prostate cancer cells, including cancer stem cells, based on a stochastic model. J Radiat Res. 2019;60(3):298-307.

72. Sharma S, Kelly TK, Jones PA. Epigenetics in cancer. Carcinogenesis. 2010;31(1):27-36.

73. Valente MJ, Henrique R, Costa VL, Jeronimo C, Carvalho F, Bastos ML, et al. A rapid and simple procedure for the establishment of human normal and cancer renal primary cell cultures from surgical specimens. PLoS ONE. 2011:6(5):e19337.

74. Wang Y, Jadhav RR, Liu J, Wilson D, Chen Y, Thompson IM, et al. Roles of distal and genic methylation in the development of prostate tumorigenesis revealed by genome-wide DNA methylation analysis. Sci Rep. 2016;6:22051.

75. Rasmussen KD, Helin K. Role of TET enzymes in DNA methylation, development, and cancer. Genes Dev. 2016;30(7):733-50

76. Zelic R, Fiano V, Grasso C, Zugna D, Pettersson A, Gillio-Tos A, et al. Global DNA hypomethylation in prostate cancer development and progression: a systematic review. Prostate Cancer Prostatic Dis. 2015;18(1):1-12.

77. Fiano V, Zugna D, Grasso C, Trevisan M, Delsedime L, Molinaro L, et al. LINE-1 methylation status in prostate cancer and non-neoplastic tissue adjacent to tumor in association with mortality. Epigenetics. 2017:12(1):11-8.

78. Gravina GL, Ranieri G, Muzi P, Marampon F, Mancini A, Di Pasquale $B$, et al. Increased levels of DNA methyltransferases are associated with the tumorigenic capacity of prostate cancer cells. Oncol Rep. 2013;29(3):1189-95

79. Bakavicius A, Daniunaite K, Zukauskaite K, Barisiene M, Jarmalaite S, Jankevicius F. Urinary DNA methylation biomarkers for prediction of prostate cancer upgrading and upstaging. Clin Epigenetics. 2019:11(1):115

80. Chen Y, Li J, Yu X, Li S, Zhang X, Mo Z, et al. APC gene hypermethylation and prostate cancer: a systematic review and meta-analysis. Eur J Hum Genet. 2013;21(9):929-35.

81. Audia JE, Campbell RM. Histone modifications and cancer. Cold Spring Harb Perspect Biol. 2016:8(4):a019521.

82. Cimadamore A, Gasparrini S, Scarpelli M, Doria A, Mazzucchelli R, Massari F, et al. Epigenetic Modifications and Modulators in Prostate Cancer. Crit Rev Oncog. 2017;22(5-6):439-50.

83. Ngollo M, Lebert A, Daures M, Judes G, Rifai K, Dubois L, et al. Global analysis of H3K27me3 as an epigenetic marker in prostate cancer progression. BMC Cancer. 2017;17(1):261.

84. Daures M, Idrissou M, Judes G, Rifaï K, Penault-Llorca F, Bignon YJ, et al. A new metabolic gene signature in prostate cancer regulated by JMJD3 and EZH2. Oncotarget. 2018;9(34):23413-25.

85. Ren G, Baritaki S, Marathe H, Feng J, Park S, Beach S, et al. Polycomb protein $\mathrm{EZH} 2$ regulates tumor invasion via the transcriptional repression of the metastasis suppressor RKIP in breast and prostate cancer. Cancer Res. 2012;72(12):3091-104.

86. Tamgue O, Lei M. Triptolide promotes senescence of prostate cancer cells through histone methylation and heterochromatin formation. Asian Pac J Cancer Prev. 2017;18(9):2519-26.

87. Crea F, Sun L, Mai A, Chiang YT, Farrar WL, Danesi R, et al. The emerging role of histone lysine demethylases in prostate cancer. Mol Cancer. 2012;11:52.

88. Choi KC, Park S, Lim BJ, Seong AR, Lee YH, Shiota M, et al. Procyanidin B3, an inhibitor of histone acetyltransferase, enhances the action of 
antagonist for prostate cancer cells via inhibition of p300-dependent acetylation of androgen receptor. Biochem J. 2011;433(1):235-44.

89. Lee JH, Yang B, Lindahl AJ, Damaschke N, Boersma MD, Huang W, et al. Identifying dysregulated epigenetic enzyme activity in castrate-resistant prostate cancer development. ACS Chem Biol. 2017;12(11):2804-14.

90. denDekker AD, Davis FM, Joshi AD, Wolf SJ, Allen R, Lipinski J, et al. TNF-a regulates diabetic macrophage function through the histone acetyltransferase MOF. JCI Insight. 2020;5(5):e132306.

91. Weichert W, Röske A, Gekeler V, Beckers T, Stephan C, Jung K, et al. Histone deacetylases 1,2 and 3 are highly expressed in prostate cancer and HDAC2 expression is associated with shorter PSA relapse time after radical prostatectomy. Br J Cancer. 2008;98(3):604-10.

92. Camacho-Moctezuma B, Quevedo-Castillo M, Melendez-Zajgla J, Aquino-Jarquin G, Martinez-Ruiz GU. YY1 negatively regulates the XAF1 gene expression in prostate cancer. Biochem Biophys Res Commun. 2019;508(3):973-9.

93. Shinojima T, Yu Q, Huang SK, Li M, Mizuno R, Liu ET, et al. Heterogeneous epigenetic regulation of TIMP3 in prostate cancer. Epigenetics. 2012;7(11):1279-89.

94. Fortson WS, Kayarthodi S, Fujimura Y, Xu H, Matthews R, Grizzle WE, et al. Histone deacetylase inhibitors, valproic acid and trichostatin-A induce apoptosis and affect acetylation status of p53 in ERG-positive prostate cancer cells. Int J Oncol. 2011;39(1):111-9.

95. Ai J, Wang Z. HDAC6 Regulation of Androgen Signaling in Prostate Cancer. 2013. p. 443-59.

96. Yang Y, Tse AK, Li P, Ma Q, Xiang S, Nicosia SV, et al. Inhibition of androgen receptor activity by histone deacetylase 4 through receptor SUMOylation. Oncogene. 2011;30(19):2207-18

97. Haider R, Massa F, Kaminski L, Clavel S, Djabari Z, Robert G, et al. Sirtuin 7: a new marker of aggressiveness in prostate cancer. Oncotarget. 2017:8(44):77309-16.

98. Kim JG, Park MT, Heo K, Yang KM, Yi JM. Epigenetics meets radiation biology as a new approach in cancer treatment. Int J Mol Sci. 2013;14(7):15059-73.

99. Oronsky B, Scicinski J, Kim MM, Cabrales P, Salacz ME, Carter CA, et al. Turning on the radio: epigenetic inhibitors as potential radiopriming agents. Biomolecules. 2016;6(3):32.

100. Friedl AA, Mazurek B, Seiler DM. Radiation-induced alterations in histone modification patterns and their potential impact on short-term radiation effects. Front Oncol. 2012;2:117.

101. Stone L. Prostate cancer: radiotherapy induces epigenetic changes. Nat Rev Urol. 2016:13(5):241

102. Sutton LP, Jeffreys SA, Phillips JL, Taberlay PC, Holloway AF, Ambrose $\mathrm{M}$, et al. DNA methylation changes following DNA damage in prostate cancer cells. Epigenetics. 2019;14(10):989-1002.

103. Zhu $X$, Wang $Y$, Tan L, Fu X. The pivotal role of DNA methylation in the radio-sensitivity of tumor radiotherapy. Cancer Med. 2018;7(8):3812-9.

104. Armstrong CA, Jones GD, Anderson R, Iyer P, Narayanan D, Sandhu J, et al. DNMTs are required for delayed genome instability caused by radiation. Epigenetics. 2012;7(8):892-902.

105. Gorodetska I, Lukiyanchuk V, Peitzsch C, Kozeretska I, Dubrovska A BRCA1 and EZH2 cooperate in regulation of prostate cancer stem cell phenotype. Int J Cancer. 2019;145(11):2974-85.

106. Nolan KD, Franco OE, Hance MW, Hayward SW, Isaacs JS. Tumorsecreted $\mathrm{Hsp} 90$ subverts polycomb function to drive prostate tumor growth and invasion. J Biol Chem. 2015;290(13):8271-82.

107. Pang J, Yang YW, Huang Y, Yang J, Zhang H, Chen R, et al. P110ß inhibition reduces histone H3K4 di-methylation in prostate cancer. Prostate. 2017;77(3):299-308

108. Makarević J, Tawanaie N, Juengel E, Reiter M, Mani J, Tsaur I, et al. Crosscommunication between histone $\mathrm{H} 3$ and $\mathrm{H} 4$ acetylation and Akt-mTOR signalling in prostate cancer cells. J Cell Mol Med. 2014;18(7):1460-6.

109. Abbas A, Gupta S. The role of histone deacetylases in prostate cancer. Epigenetics. 2008;3(6):300-9.

110. Komura K, Yoshikawa Y, Shimamura T, Chakraborty G, Gerke TA, Hinohara $\mathrm{K}$, et al. ATR inhibition controls aggressive prostate tumors deficient in Y-linked histone demethylase KDM5D. J Clin Investig. 2018;128(7):2979-95.

111. Bayo J, Tran TA, Wang L, Peña-Llopis S, Das AK, Martinez ED. Jumonji inhibitors overcome radioresistance in cancer through changes in $\mathrm{H3K} 4$ methylation at double-strand breaks. Cell Rep. 2018;25(4):1040-50.e5.

112. Fan L, Xu S, Zhang F, Cui X, Fazli L, Gleave M, et al. Histone demethylase JMJD1A promotes expression of DNA repair factors and radio-resistance of prostate cancer cells. Cell Death Dis. 2020;11(4):214.

113. Vieira FQ, Costa-Pinheiro P, Almeida-Rios D, Graça I, Monteiro-Reis S, Simões-Sousa S, et al. SMYD3 contributes to a more aggressive phenotype of prostate cancer and targets Cyclin D2 through H4K2Ome3. Oncotarget. 2015;6(15):13644-57.

114. Jonsson M, Ragnum HB, Julin CH, Yeramian A, Clancy T, Frikstad KM, et al. Hypoxia-independent gene expression signature associated with radiosensitisation of prostate cancer cell lines by histone deacetylase inhibition. Br J Cancer. 2016;115(8):929-39.

115. Gao S, Chen S, Han D, Wang Z, Li M, Han W, et al. Chromatin binding of FOXA1 is promoted by LSD1-mediated demethylation in prostate cancer. Nat Genet. 2020;52(10):1011-7.

116. Mosammaparast N, Kim H, Laurent B, Zhao Y, Lim HJ, Majid MC, et al. The histone demethylase LSD1/KDM1A promotes the DNA damage response. J Cell Biol. 2013;203(3):457-70.

117. Wang J, Yu Q, Qiu Z, Dai T, Wang S, Yang X, et al. The combined effect of epigenetic inhibitors for LSD1 and BRD4 alters prostate cancer growth and invasion. Aging (Albany NY). 2020;12(1):397-415.

118. Li X, Baek G, Ramanand SG, Sharp A, Gao Y, Yuan W, et al. BRD4 promotes DNA repair and mediates the formation of TMPRSS2-ERG gene rearrangements in prostate cancer. Cell Rep. 2018;22(3):796-808.

119. Shi W, Lawrence YR, Choy H, Werner-Wasik M, Andrews DW, Evans JJ, et al. Vorinostat as a radiosensitizer for brain metastasis: a phase I clinical trial. J Neurooncol. 2014;118(2):313-9.

120. Choi CYH, Wakelee HA, Neal JW, Pinder-Schenck MC, Yu HM, Chang SD, et al. Vorinostat and concurrent stereotactic radiosurgery for non-small cell lung cancer brain metastases: a phase 1 dose escalation trial. Int J Radiat Oncol Biol Phys. 2017;99(1):16-21.

121. Galanis E, Anderson SK, Miller CR, Sarkaria JN, Jaeckle K, Buckner JC, et al. Phase I/II trial of vorinostat combined with temozolomide and radiation therapy for newly diagnosed glioblastoma: results of Alliance N0874/ABTC 02. Neuro Oncol. 2018;20(4):546-56.

122. Teknos TN, Grecula J, Agrawal A, Old MO, Ozer E, Carrau R, et al. A phase 1 trial of Vorinostat in combination with concurrent chemoradiation therapy in the treatment of advanced staged head and neck squamous cell carcinoma. Invest New Drugs. 2019;37(4):702-10.

123. Krauze AV, Myrehaug SD, Chang MG, Holdford DJ, Smith S, Shih J, et al. A phase 2 study of concurrent radiation therapy, temozolomide, and the histone deacetylase inhibitor valproic acid for patients with glioblastoma. Int J Radiat Oncol Biol Phys. 2015;92(5):986-92.

124. Candelaria M, Cetina L, Pérez-Cárdenas E, de la Cruz-Hernández E, González-Fierro A, Trejo-Becerril C, et al. Epigenetic therapy and cisplatin chemoradiation in FIGO stage IIIB cervical cancer. Eur J Gynaecol Oncol. 2010;31(4):386-91.

125. Takhar HS, Singhal N, Gowda R, Penniment M, Takhar P, Brown MP. Phase I study evaluating the safety and efficacy of oral panobinostat in combination with radiotherapy or chemoradiotherapy in patients with inoperable stage III non-small-cell lung cancer. Anticancer Drugs. 2015;26(10):1069-77.

126. Shi W, Palmer JD, Werner-Wasik M, Andrews DW, Evans JJ, Glass J, et al. Phase I trial of panobinostat and fractionated stereotactic reirradiation therapy for recurrent high grade gliomas. J Neurooncol. 2016:127(3):535-9.

\section{Publisher's Note}

Springer Nature remains neutral with regard to jurisdictional claims in published maps and institutional affiliations. 